\title{
A girl with a giant fibrolipoma in her thoracic cavity: a rare case report
}

\author{
Gang Wang ${ }^{1}$ Chun Wu' ${ }^{1}$, Yi Wang ${ }^{2}$ and Jiangtao Dai ${ }^{1,3^{*}}$
}

\begin{abstract}
Background: Fibrolipoma is an uncommon subtype of lipoma. On the basis of the results of a survey of the PubMed database, only approximately a dozen cases in children have been described in which the histological diagnosis of fibrolipoma has been confirmed. In children, fibrolipomas have been reported in the eyelids, ears, lips, nasopharynx, mouth, and other locations but not in the thoracic cavity. We present the case of a 15-year-old girl with a giant fibrolipoma in the left side of her thoracic cavity.

Case presentation: A 15-year-old Chinese girl presented with chest tightness and exercise-induced shortness of breath of 4 months' duration. Computed tomography revealed a giant mixed-density space-occupying lesion in the left side of her thoracic cavity, originating possibly from the pleura. Radiological findings were inconclusive and failed to exclude malignant mesenchymal tumor. After excluding malignant tumor with two needle biopsies and identifying the tumor's feeding blood vessels by computed tomography angiography examination, our treatment plan was, first, embolization of the tumor's blood vessels by digital subtraction angiography and, second, to remove the tumor by thoracotomy.

Conclusions: Thoracic fibrolipoma in children is rare; its treatment is complete resection of the tumor. Pathological examination of the removed tissue is the gold standard for diagnosis. Early computed tomography and magnetic resonance imaging examinations are helpful to determine the extent and nature of the tumor and to reduce damage of the surrounding organs. Preoperative examination of tumor markers, ultrasound-guided biopsy, and preoperative digital subtraction angiography tumor vascular embolization are important preoperative preparations to ensure surgical resection.
\end{abstract}

Keywords: Fibrolipoma, Thoracic cavity, Case report

\section{Introduction}

Fibrolipoma is an uncommon subtype of lipoma [1]; it is characterized by the presence of adipose tissue and abundant amounts of fibrous tissues in the tumor that are completely separated from surrounding tissues [1-3]. On the basis of the results of a survey of the PubMed database [4-12], only approximately a dozen cases in children have been reported in which the histological diagnosis of fibrolipoma has been confirmed. In children, fibrolipomas have been reported in the eyelids, ears, lips, nasopharynx,

\footnotetext{
* Correspondence: daijiangtao2001@aliyun.com

'Department of Cardio-Thoracic Surgery, Children's Hospital, Chongqing Medical University, Chongqing, People's Republic of China

${ }^{3}$ Ministry of Education Key Laboratory of Child Development and Disorders,

China International Science and Technology Cooperation Base of Child

Development and Critical Disorders, Chongqing Key laboratory of Pediatrics,

Chongqing 400014, China

Full list of author information is available at the end of the article
}

mouth, esophagus, peritoneum, and other locations but not in the thoracic cavity. To aid clinicians in further understanding the clinical manifestations, diagnosis, and treatment of children with thoracic fibrolipoma, we present the case of a 15-year-old girl with a giant fibrolipoma in the left side of her thoracic cavity.

\section{Case presentation}

A 15-year-old Chinese girl, a rural middle school student, presented with chest tightness and exercise-induced shortness of breath of 4 months' duration. During this time, she had no obvious explanation for the gradual development of exercise-induced shortness of breath, with occasional pain in her left shoulder and back, chest tightness, limited activity, occasional cough, no fever, no hot flashes, no night sweats, and no weight loss. She was able to climb only two to three flights of stairs before

(c) The Author(s). 2019 Open Access This article is distributed under the terms of the Creative Commons Attribution 4.0 International License (http://creativecommons.org/licenses/by/4.0/), which permits unrestricted use, distribution, and 


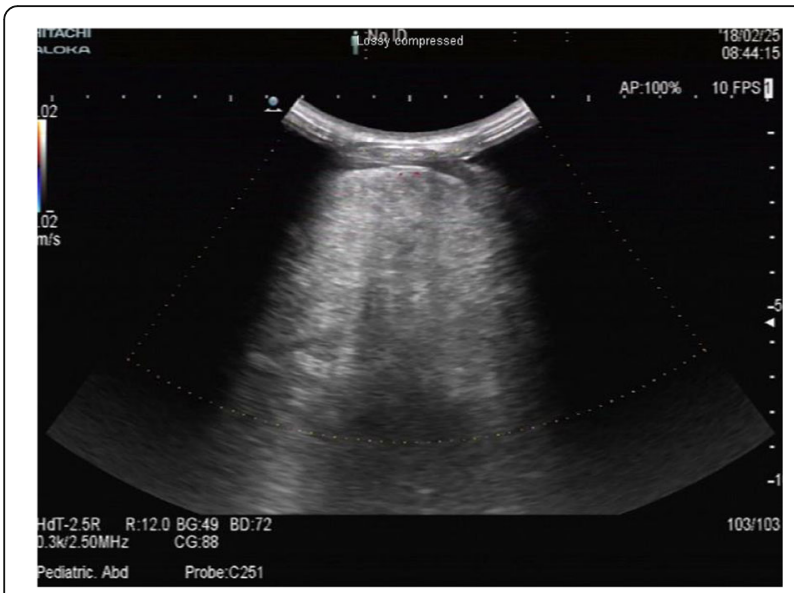

Fig. 1 Giant substantial echo of the chest

resting. In the past 4 months she had not sought treatment because of her heavy learning load and insufficient attention from her parents. She was brought to our hospital by her parents for treatment because the chest tightness and the shortness of breath became more severe after activity. A physical examination on admission revealed body temperature of $36.5{ }^{\circ} \mathrm{C}$ pulse of 95 beats/minute, and blood pressure of $105 / 60 \mathrm{mmHg}$; there were no abnormalities in a neurological examination. A medical examination by a specialist revealed no cyanosis or dyspnea at rest. Her left thorax was full with flatness to percussion. There was breath sound asymmetry, with absence of breath sounds on the left and no dry or wet rales. The apex of her heart beat was located in the midline of her right clavicle. Blood analysis revealed white blood cells (WBC) of $5.15 \times 10^{9} / \mathrm{L}$, platelets (PLT) of $118 \times 10^{9} / \mathrm{L}$, red blood cells (RBC) of $5.15 \times 10^{12} / \mathrm{L}$, and hemoglobin (HB) of $144 \mathrm{~g} / \mathrm{L}$; liver and kidney function were normal. Tumor markers were as follows: alpha fetoprotein (AFP) $0.46 \mathrm{ng} /$ $\mathrm{ml}$, human chorionic gonadotropin (hCG) $<1 \mathrm{mIU} / \mathrm{ml}$, ferritin $152 \mathrm{ng} / \mathrm{ml}$, neuron-specific enolase (NSE) $12.4 \mathrm{ng} /$ $\mathrm{ml}$, urinary vanillylmandelic acid (VMA) $7.82 \mathrm{mg} / 24$ hours. Chest color Doppler ultrasonography revealed a giant tumor with substantial echo and irregular shape. Color Doppler flow imaging (CDFI) revealed substantial visible star-like blood flow signals in the left side of her thoracic cavity (Fig. 1). Enhanced computed tomography (CT) revealed a giant mixed-density mass in the left side of her thoracic cavity, part of which was fat density, measuring $323.6 \mathrm{~mm} \times 193.1 \mathrm{~mm} \times 175.6 \mathrm{~mm}$. The enhancement of the parenchymal part of the tumor was not obvious, but it was slightly enhanced after a delay. Tumor vessels were seen in the arterial phase. Her left lung was substantially compressed into dense shadows. Her mediastinum, heart, and thoracic aorta were substantially compressed and pushed to the right. Her right lung was also compressed without hilar lymph node enlargement. The left eighth posterior intercostal artery was enlarged and the branches of the vessels entered the tumor. The branching vessels of the celiac trunk also sent enlarged and twisted branches into the tumor. Airway reconstruction revealed that her trachea and bronchus were compressed, the left part of the bronchus and the distal end were not seen, and her left diaphragm was depressed. A CT scan revealed a giant mixed-density space-occupying lesion in the left side of her thoracic cavity, originating possibly from the pleura. Radiological findings were unable to excluded malignant mesenchymal tumor (Fig. 2a, b).

Because of the giant tumor and the inability to exclude malignant mesenchymal tumor on radiological findings, a fine-needle aspiration biopsy was performed under ultrasound guidance to clarify the nature of the tumor. Pathological examination revealed mature fibrous adipose tissue and striated muscle tissue (Fig. 3a). However, the pathologists were suspicious of the result in relation to the
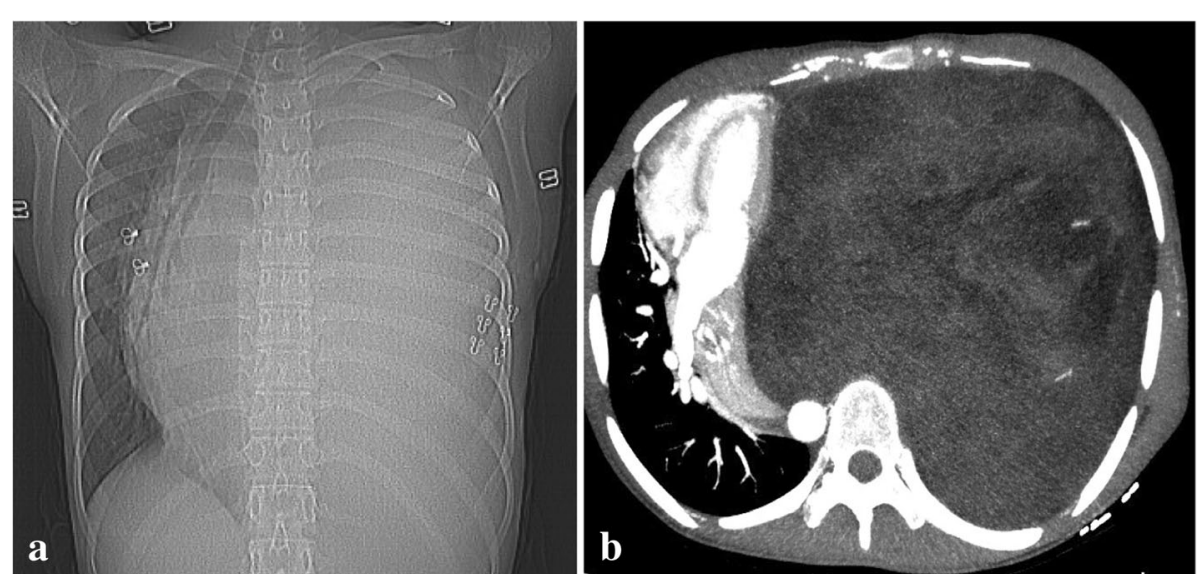

Fig. 2 Computed tomography angiography images (a is sagittal image and $\mathbf{b}$ is cross-sectional image), giant mixed density masses, substantial compression of the left lung and heart 


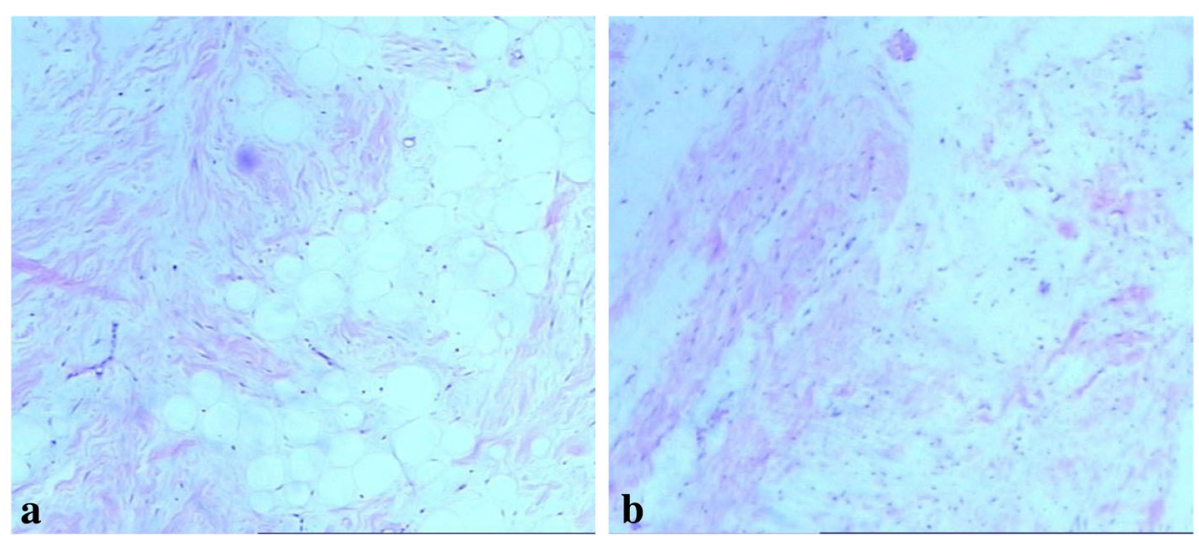

Fig. 3 a First pathological examination; b second pathological examination. Both microphotograph showing mature fibrous adipose tissue, striated muscle tissue and rich mesodermal tissue (hematoxylin and eosin, $\times 100$ )

CT scan and suggested that the tumor be re-examined; therefore, an ultrasound-guided percutaneous needle biopsy was performed again. The second time, the pathological diagnosis was possible teratoma with mature fibrous adipose tissue, striated muscle tissue, and rich mesodermal tissue (Fig. 3b).

After excluding malignant tumor with two needle biopsies and identifying the tumor's feeding blood vessels by CT angiography (CTA) examination, our treatment plan was, first, embolization of the tumor's blood vessels by digital subtraction angiography (DSA) and then, second, to remove the tumor by thoracotomy. DSA revealed that approximately $70 \%$ of the tumor was supplied by an enlarged branch of the target artery at the left eighth intercostal space, and approximately $20 \%$ of the tumor was supplied by the branch of the target artery in the celiac trunk (Fig. 4a, b). Using a 0.035 inch $\times 150 \mathrm{~cm}$ guidewire and a $2.7 \mathrm{~F}$ microcatheter, a $560 \mu \mathrm{m}$ gelatin sponge+contrast medium $15 \mathrm{ml}$ suspension was injected through the microcatheter to achieve embolization of the two target arteries. After DSA embolization, the result was satisfactory (Fig. 4c).
She had a mild febrile reaction after embolization. On the third day after embolization, she underwent thoracotomy through the left fifth costal oblique incision. The lesion occupied the entire left side of her thoracic cavity; the tumor had a solid intact capsule and moderate texture (Fig. 5a). Her left lung was severely compressed, her left hemidiaphragm was depressed, and her mediastinum, heart, and thoracic aorta were displaced to the right. After the tumor was partly removed from the center, the remaining tumor was removed from the left side of her thoracic cavity by being folded up and down. To avoid the occurrence of recurrent pulmonary edema, her left lung was suppressed by hand for approximately 15 minutes after removing the tumor and the lung was slowly re-expanded (Fig. 5b). The lesion size was approximately $360 \mathrm{~mm} \times 200 \mathrm{~mm} \times 180 \mathrm{~mm}$, and the tumor weight was approximately $6.1 \mathrm{~kg}$ (Fig. 5c).

Postoperative pathological results were as follows: there was adipose tissue hyperplasia in the wide fiber interval; immunohistochemistry revealed melanA (-), desmin (-), Ki67 individual cells (+), CD34 fibers and

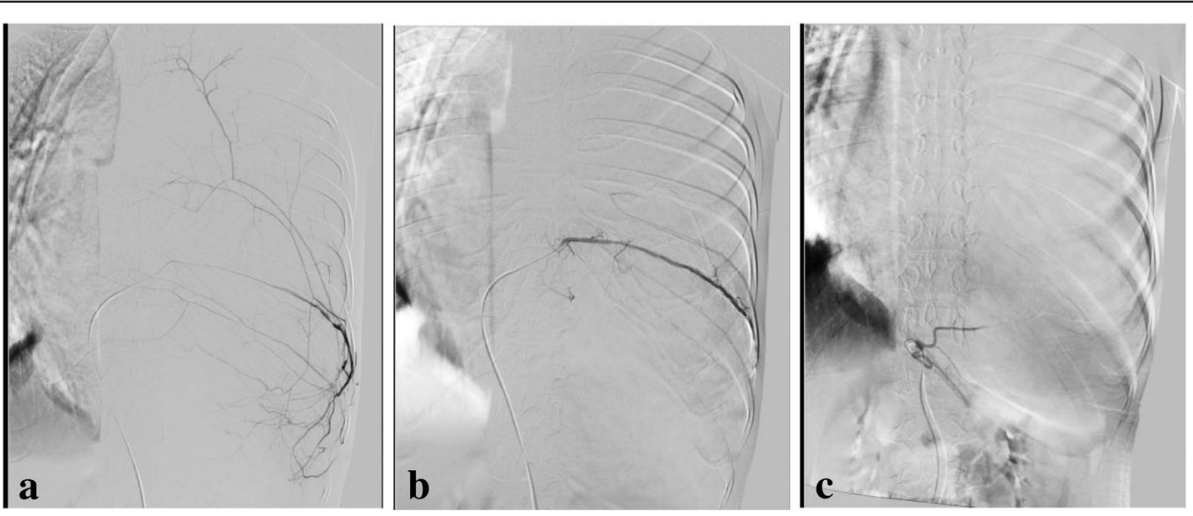

Fig. 4 a Approximately $70 \%$ of the tumor was supplied by an enlarged branch of the target artery at the left eighth intercostal space. $\mathbf{b}$ Approximately $20 \%$ of the tumor was supplied by the branch of the target artery in the celiac trunk. c Embolize the two target arteries 

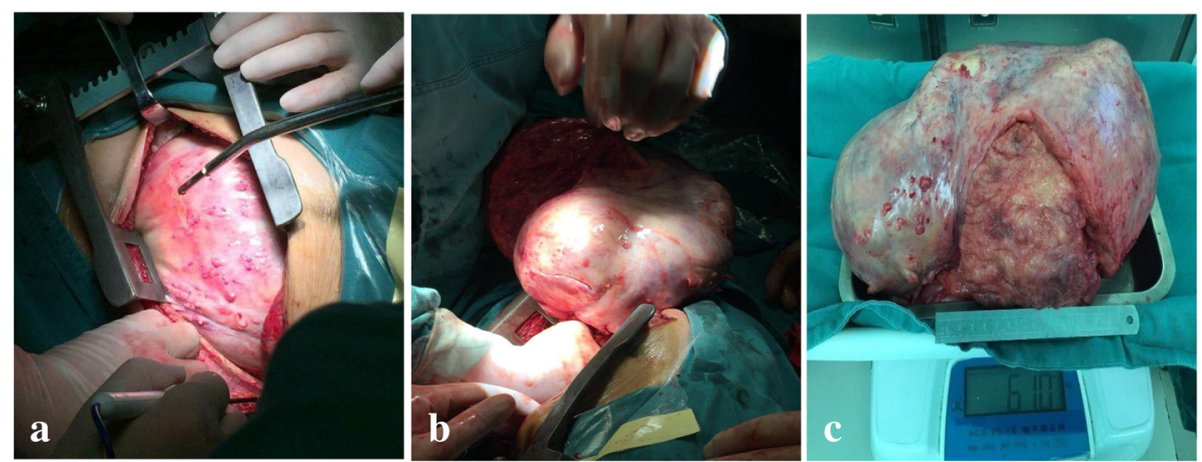

Fig. 5 a Tumor shape in the thoracic; $\mathbf{b}$ tumor shape after removal of thoracic cavity; c tumor weighing

blood vessels $(+)$, bcl-2 (-), s100 (+), and smooth muscle actin (SMA) blood vessels $(+)$ (Fig. 6a, b). The pathological diagnosis was fibrolipoma.

CT results 1 week after surgery revealed no tumor in our patient's thoracic cavity. The upper lobe of her left lung was substantially consolidated with several cystic lesions of various sizes (Fig. 7). After two fibrobronchoscopy treatments, CT results 1 month after surgery revealed improved atelectasis with several persistent cystic lesions in the left lung (Fig. 8). CT results 6 months after surgery revealed that the several cystic lesions of various sizes in her left lung did not improve compared with the previous result (Fig. 9). She was recommended to follow up for 1 or 2 years. If there were still cystic lesions in her left lung, her pulmonary cystic lesions would be removed.

Therefore, for giant thoracic tumors, if malignant tumor cannot be excluded before surgery and it is thought that they pose a high risk of bleeding during the operation, we recommend ultrasound-guided biopsy first, then DSA tumor vascular embolization, and finally surgical resection. The girl's huge thoracic tumor was safely and completely removed by this method, and the prognosis is good. Otherwise, it may lead to unresectable tumors and the risk of massive hemorrhage.

\section{Discussion}

Thoracic tumors of children are common in neurogenic, tracheal, and esophageal tumors of the posterior mediastinum as well as in lymphoma, leukemia, thymoma, and teratoma of the anterior mediastinum. Pulmonary blastoma, myofibroblastoma, pleural mesothelioma, liposarcoma, and others are rare. It is essential to know the nature and size of thoracic tumors because the treatments will be quite different. Lipoma is a benign tumor composed of mature adipocytes. If there are many fibrous tissues in the lipoma, it is called a fibrolipoma. These characteristically grow by simple expansion in a well-encapsulated fashion without the tissue infiltration that is more characteristic of liposarcomas [13]. Because fibrous tissues and adipose tissues are tumor parenchyma and the texture is slightly tough $[2,14,15]$, they are classified as variants of conventional lipoma by the World Health Organization (WHO). Reported cases of fibrolipoma in recent years show that they can invade several parts of the body, including the face, lips, throat,

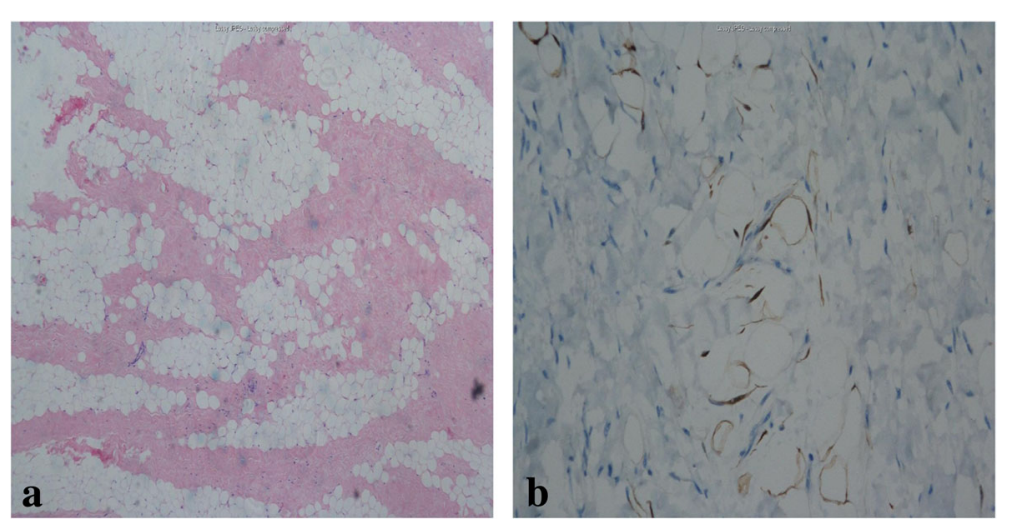

Fig. 6 a Microphotograph showing adipose tissue hyperplasia in the wide fiber interval (hematoxylin and eosin, $\times 40)$ b SMA blood vessels $(+)$, (immunohistochemistry image $\times 100$ ) 


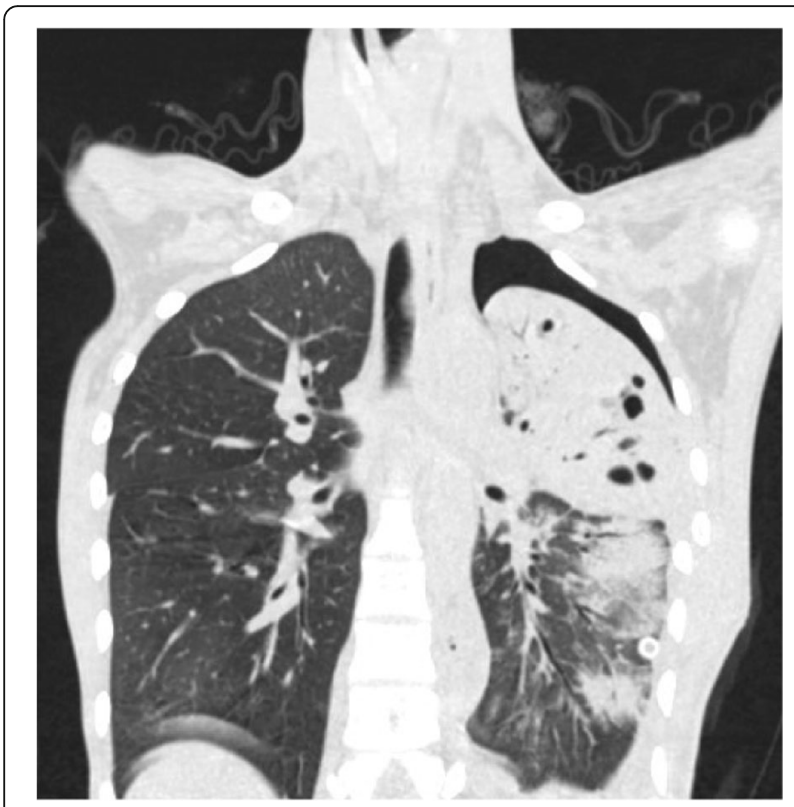

Fig. 7 Computed tomography image 1 week after operation: substantial consolidation and several cystic lesions of various sizes

trachea, esophagus, spermatic cord, abdominal cavity, and other locations [4-16]; however, there have been no reports of occurrence in children's thoracic cavity. The clinical features of fibrolipomas vary according to their rate of growth, size, and location. On clinical examination, a fibrolipoma usually presents as an asymptomatic and slowly growing mass [1, 14]; therefore, it is difficult to value the incidence of the tumor. There is no definite etiology of fibrolipoma. Some authors believe that it is congenital, caused by endocrine disorders, or that it is a product of degenerative fibrous tumors, or is caused by the maturation of lipoblastoma [16]; its treatment is

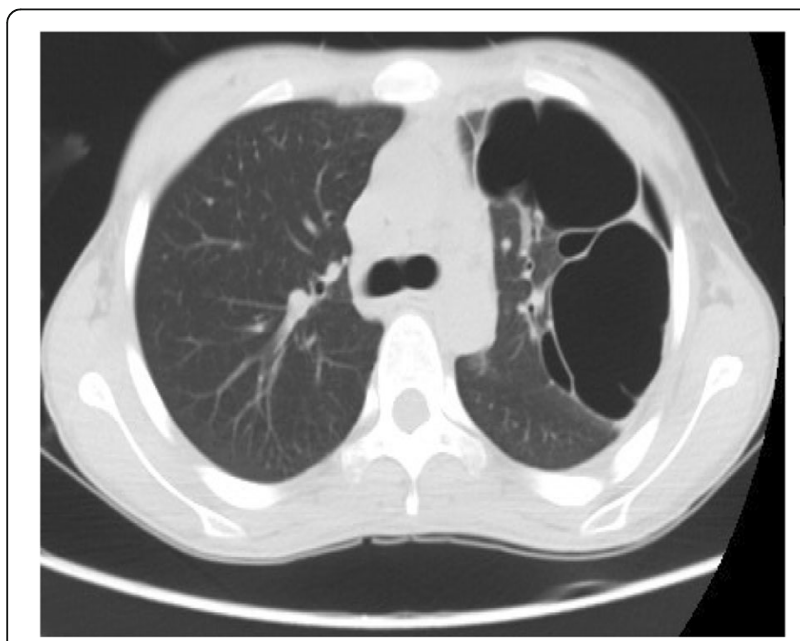

Fig. 8 Computed tomography image 1 month after surgery: consolidation improved and cystic lesions did not decrease

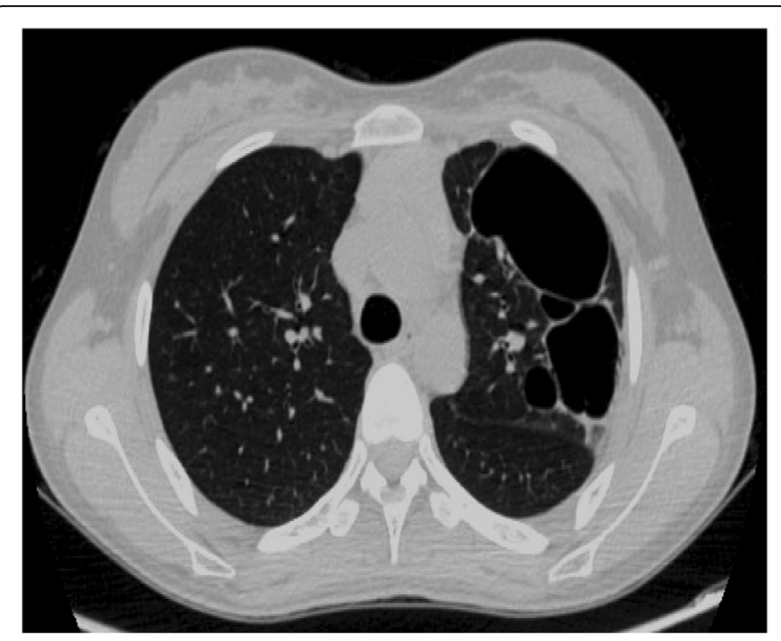

Fig. 9 Computed tomography image 6 months after operation: cystic lesions did not improve

complete surgical resection. In the present case, our patient had no systemic disease or any history of trauma initially, as well as no family history of fibrolipoma, but she sought medical help when it appeared as a symptom and a functional problem. Because of its giant size, the case should be differentiated from lipoma, pulmonary blastoma, pleural mesothelioma, thoracic myofibroblastoma, and liposarcoma, especially from the latter that can be divided into well-differentiated and poorly differentiated liposarcoma. Well-differentiated liposarcoma contains many fat components and has clear borders and regular morphology. Sometimes, it is difficult to differentiate; however, necrotic cystic change or calcification in the tumor is helpful for making the differential diagnosis. It is easy to differentiate poorly differentiated and highly malignant liposarcoma with irregular morphology and infiltration into surrounding tissues containing a small amount of, or even no, fatty tissue. Ultrasoundguided biopsy is a reliable method of identification; however, the case was also misdiagnosed as teratoma.

It is a problem for surgeons to determine how to safely and effectively treat giant thoracic tumors of children. In this case, the first ultrasound-guided needle biopsy was performed to exclude malignant tumors, then embolization of the tumor vessels was accomplished by DSA to reduce intraoperative bleeding, and, finally, the whole tumor was removed. Although the tumor was giant and the visual field was poor, the tumor could be resected from a part to the whole because of a complete capsule and the reduction of the tumor's blood supply after embolization by DSA. In particular, the heart, large vessels, esophagus, and trachea should be protected during surgery. Furthermore, another important treatment step is that the surgeon needs to suppress the affected lung by hand for about a dozen minutes and loosen slowly to avoid re-expansion pulmonary edema 
after resection of the giant thoracic tumor. Due to insufficient attention from parents and children, long-term compression of giant tumors results in pulmonary cystic lesions. If the cystic lesions do not improve after 1 or 2 years, it may be possible to remove them by reoperation.

\section{Conclusion}

Thoracic fibrolipoma in children is rare; its treatment is complete resection of the tumor. Pathological examination of the removed tissue is the gold standard for diagnosis. Early CT and MRI examinations are helpful to determine the extent and nature of the tumor and to reduce damage to the surrounding organs. Preoperative examination of tumor markers, ultrasound-guided biopsy, and preoperative DSA tumor vascular embolization are important preoperative preparations to ensure surgical resection. The protection of the affected lung during surgery is also a problem that surgeons should not ignore.

\section{Abbreviations}

AFP: Alpha fetoprotein; CDFl: Color Doppler flow imaging; CT: Computed tomography; CTA: Computed tomography angiography; DSA: Digital subtraction angiography; HB: Hemoglobin; hCG: Human chorionic gonadotropin; NSE: Neuron-specific enolase; PLT: Platelets; RBC: Red blood cells; SMA: Smooth muscle actin; VMA: Vanillylmandelic acid; WBC: White blood cells; WHO: World Health Organization

\section{Acknowledgements}

We thank Professor Chun Wu for providing technical assistance and for insightful discussions during the preparation of the manuscript.

\section{Funding}

No financial support.

\section{Authors' contributions}

CW, JD, and GW were involved in operation and management in hospital; YW was involved in the care of the patient over the course of her admissions. JD did the literature research and wrote the first draft of the report, which was further edited by all authors. All authors had full access to the data and vouch for their integrity and accuracy. The corresponding author had final responsibility for the decision to submit for publication. GW and CW contributed the first authorship. JD contributed correspondent author. Final approval of the version to be published: JD. The authors were solely responsible for final review and approval of the report.

\section{Ethics approval and consent to participate}

All procedures performed in studies involving human participants were in accordance with the ethical standards of the institutional and/or national research committee and with the 1964 Helsinki Declaration and its later amendments or comparable ethical standards; for retrospective studies, ethical approval is not required. This article does not contain any studies with human participants performed by any of the authors.

\section{Consent for publication}

Written informed consent was obtained from the patient's legal guardian(s) for publication of this case report and any accompanying images. A copy of the written consent is available for review by the Editor-in-Chief of this journal.

\section{Competing interests}

The authors declare that they have no competing interests.

\section{Publisher's Note}

Springer Nature remains neutral with regard to jurisdictional claims in published maps and institutional affiliations.

\section{Author details}

'Department of Cardio-Thoracic Surgery, Children's Hospital, Chongqing Medical University, Chongqing, People's Republic of China. ${ }^{2}$ Pediatric Intensive Care Unit, Children's Hospital, Chongqing Medical University, Chongqing, China. ${ }^{3}$ Ministry of Education Key Laboratory of Child Development and Disorders, China International Science and Technology Cooperation Base of Child Development and Critical Disorders, Chongqing Key laboratory of Pediatrics, Chongqing 400014, China.

Received: 3 December 2018 Accepted: 27 February 2019

Published online: 07 May 2019

\section{References}

1. Jung SN, Shin JW, Kwon H, Yim YM. Fibrolipoma of the tip of the nose. J Craniofac Surg. 2009;20(2):555-6.

2. Kim MH, Sa HS, Woo K, Kim YD. Fibrolipoma of the orbit. Ophthal Plast Reconstr Surg. 2011;27(1):e16-8.

3. Coban YK, Coskun A. Giant fibrolipoma mimicking abdominal lipodystrophy Indian J Plast Surg. 2008;41(1):97-8.

4. Rafael CO, Nelly RP, María EO. Fibrolipoma on upper eyelid in child. GMS Ophthalmol Cases. 2016;17:6. Doc03

5. laconetta G, Friscia M, Cecere A, Romano A, Orabona GD, et al. Rare fibrolipoma of the tongue: a case report. J Med Case Rep. 2015;9:177.

6. Shi J, Zhang J, Ding M. Lower lip cleft, bifid tongue and fibrolipoma: a case report of rare congenital anomaly. Br J Oral Maxillofac Surg. 2014:52(7):e36-8.

7. Kau RL, Patel AB, Hinni ML. Giant fibrolipoma of the esophagus. Case Rep Otolaryngol. 2012;2012:406167.

8. Manjunatha BS, Pateel GS, Shah V. Oral fibrolipoma-a rare histological entity: report of 3 cases and review of literature. J Dent (Tehran). 2010;7(4):226-31.

9. Fatih B, Mustafa H, Tolga C, Yucel M. An incidental giant preperitoneal fibrolipoma diagnosed during laparoscopic cholecystectomy. Turk J Surg. 2018:34(2):143-5.

10. Hussain J, AlZamel HA, Nawaz I, Bader AA. A case of large deep fibrolipoma in the left subclavicular region that compromised the branchial plexus and thoracic duct: A case report. Int J Surg Case Rep. 2018;48:139-41.

11. Dastoor PP, Patil RU, Singh Chauhan R, Palaskar SJ, Shah DR. Fibrolipoma on a Child's Lip: A Rare Clinical Finding. J Dent Child (Chic). 2018:85(1):36-9.

12. Chander B, Krishna M, Thakur S, Mahajan N, Vij A, et al. Extremely rare giant retroperitoneal fibrolipoma: a case report. J Cancer Res Ther. 2012;8(2):314-6

13. Rydholm A, Berg NO. Site, size and clinical incidence of lipoma. Factors in the differential diagnosis of lipoma and sarcoma. Acta Orthop Scand. 1983:54:929-34

14. Ozturk M, Ila K, Kara A, Iseri M. Fibrolipoma of the nasal septum; report of the first case. J Otolaryngol Head Neck Surg. 2013:42:11.

15. Capodiferro S, Maiorano E, Scarpelli F, Favia G. Fibrolipoma of the lip treated by diode laser surgery: a case report. J Med Case Rep. 2008;2:301.

16. Kumaraswamy S, Madan N, Keerthi R, Shakti S. Lipomas of oral cavity: case reports with review of literature. J Maxillofac Oral Surg. 2009;8(4):394-7.

Ready to submit your research? Choose BMC and benefit from:

- fast, convenient online submission

- thorough peer review by experienced researchers in your field

- rapid publication on acceptance

- support for research data, including large and complex data types

- gold Open Access which fosters wider collaboration and increased citations

- maximum visibility for your research: over $100 \mathrm{M}$ website views per year

At BMC, research is always in progress.

Learn more biomedcentral.com/submissions 